\title{
DNA Repair, Dysplastic Nevi, and Sunlight Sensitivity in the Development of Cutaneous Malignant Melanoma
}

\author{
Maria Teresa Landi, Andrea Baccarelli, Robert E. Tarone, Angela Pesatori, \\ Margaret A. Tucker, Mohammad Hedayati, Lawrence Grossman
}

Background: Exposure to UV radiation is associated with cutaneous malignant melanoma (CMM). In mammalian cells, UV radiation induces DNA damage that can be repaired by the nucleotide excision repair system. We designed this case-control study to determine whether DNA repair capacity (DRC) is associated with the risk of CMM and to identify risk factors that may interact biologically with DRC in the development of melanoma. Methods: Global DRC was measured in lymphocytes with the host-cell reactivation assay. Data were analyzed by use of multiple regression models. All statistical tests were two-sided. Results: DRC could be determined for 132 case patients with incident melanoma and for 145 age- and sex-matched control subjects. No statistically significant association between melanoma risk and DRC by itself was found (odds ratio $[O R]=1.0 ; 95 \%$ confidence interval $[\mathrm{CI}]=\mathbf{0 . 6}$ to 1.7 , adjusted for age, sex, lymphocyte viability, and sample storage time). DRC, however, strongly influenced CMM risk in individuals with a low tanning ability or dysplastic nevi. Individuals with a low tanning ability and a low DRC had a higher risk for $\mathrm{CMM}(\mathrm{OR}=\mathbf{8 . 6}$; 95\% CI $=2.7$ to 27.5 ) than individuals with a higher tanning ability and a high DRC. Likewise, individuals with dysplastic nevi and a low DRC had a higher relative risk $(O R=6.7$; 95\% $\mathrm{CI}=2.4$ to 18.6 ) than those lacking dysplastic nevi and having a high DRC. Subjects with dysplastic nevi and a high DRC had an intermediate risk. A likelihood-ratio test gave statistically significant interactions between DRC and tanning response $(P=.001)$ and between DRC and dysplastic nevus status $(P=.04)$, which were independently associated with CMM risk. Conclusions: DRC may modify the risk for melanoma in the presence of other strong risk factors, such as a low tanning ability and the presence of dysplastic nevi. The occurrence of melanoma in subjects without these risk factors appears to be independent of DRC. [J Natl Cancer Inst 2002;94:94-101]

The incidence of and mortality from cutaneous malignant melanoma (CMM) in Caucasians have increased rapidly throughout the world in recent decades (1-3). A family history of CMM, the presence of dysplastic nevi or atypical nevi, the number of nevi, skin sensitivity to sun, freckling, and fair hair, eye, and skin colors are known risk factors for melanoma (4). Although sunlight exposure (5), particularly intermittent exposure (6), has been associated with CMM (7), mechanisms of UV radiation-induced carcinogenesis are still largely unknown. UV radiation primarily leads to the formation of cyclobutane pyrimidine dimers and 6-4 photoproducts in DNA, and formation of photoproducts has been associated with skin carcinogenesis $(8,9)$. In mammalian cells, UV photoproducts are repaired by the nucleotide excision repair system $(10,11)$. Individuals with inherited defects in excision repair mechanisms (e.g., patients with xeroderma pigmentosum) are at extremely high risk of skin cancers, including melanoma $(12,13)$.

We conducted a case-control study to determine whether the capacity to repair UV radiation-damaged DNA, as measured by the host-cell reactivation assay (14) in peripheral blood lymphocytes, was associated with the risk of CMM and to identify host risk factors that may interact biologically with DNA repair capacity (DRC) to affect CMM risk.

\section{SubJects ANd Methods}

\section{Participants}

During the period from December 1994 to January 1999, 183 case patients with incident CMM (of any stage) and 179 control subjects were recruited at the Dermatology Unit of the Bufalini Hospital in Cesena, Italy. In the study period, the Bufalini Hospital examined approximately $85 \%$ of all CMM patients from

\footnotetext{
Affiliations of authors: M. T. Landi, M. A. Tucker (Genetic Epidemiology Branch), R. E. Tarone (Biostatistics Branch), Division of Cancer Epidemiology and Genetics, National Cancer Institute, Bethesda, MD; A. Baccarelli, Genetic Epidemiology Branch, Division of Cancer Epidemiology and Genetics, National Cancer Institute, and Epidemiology Research Center, University of Milan, Italy; A. Pesatori, Epidemiology Research Center, University of Milan; M. Hedayati, L. Grossman, Department of Biochemistry, Bloomberg School of Public Health, The Johns Hopkins University, Baltimore, MD.

Correspondence to: Maria Teresa Landi, M.D., Ph.D., National Institutes of Health, 6120 Executive Blvd., EPS 7114, Bethesda, MD 20892-7236 (e-mail: landim@mail.nih.gov).

See "Notes" following "References."

(C) Oxford University Press
} 
the Northern Marche and Southern Romagna areas, as verified with the Romagna region cancer registry (15) and with records of melanoma diagnoses from the main hospitals of the area. Of the 179 control subjects, 134 were spouses or close friends of the case patients, 14 were outpatients referred to the hospital because of minor accidental trauma, and 31 were healthy volunteers from the Bufalini Hospital personnel. Control subjects were frequency-matched to case patients by decade of age and sex. All of the control subjects were from the same geographic area as the case patients. The control group of hospital personnel had a statistically significantly lower DRC $(P=.01)$ and a higher cell viability $(P=.001)$ than other control groups, but no other major differences were observed. Approximately $95 \%$ of the case patients and $83 \%$ of the control subjects agreed to participate in the study. Three case patients and two control subjects reported a first-degree relative with melanoma and were excluded from the analysis. Study subjects included 183 case patients (87 males and 96 females) and 179 control subjects (89 males and 90 females) ranging in age from 17 years to 77 years. After approval of the study by the Bufalini Hospital's Ethical Committee, written informed consent was obtained from all of the participants. A standardized in-person questionnaire was administered by trained interviewers, who asked questions on lifetime residential history, exposure to UV radiation, medical and family history of cancer and other diseases, smoking habits, drug consumption, skin reaction to the first half an hour of sun exposure, tanning ability, and sunscreen use.

Tanning ability was ascertained through the following question: "After repeated and prolonged exposure to sunlight, your skin 1) becomes very tanned, 2) becomes medium tanned, 3) becomes hardly tanned, 4) has a tendency to peel, or 5) has absolutely no change." Because no one selected choice 4 and only three selected choice 5 , the answers were categorized into three groups: high tanning response (choice 1), medium tanning response (choice 2), and low tanning response (choices 3 and 5).

The same dermatologist examined all of the subjects in the study. This dermatologist examined the entire skin of each subject's body, except for the genital area, to assess pigmentation characteristics, freckling, and the presence of skin lesions or other skin cancers.

An expert oncologist, blinded to melanoma status, assessed all diagnoses of dysplastic nevi and counted the number of nevi in standardized photographs of the back of each subject. Nevus count was missing in two subjects because pictures did not include the entire back. Diagnosis of dysplastic nevi was uncertain in seven subjects; thus, dysplastic nevi were recorded as missing. Fourteen subjects lacked photographs and were excluded from the analyses in which dysplastic nevi or number of nevi were considered. The restriction of the nevus count to the back was necessary for feasibility reasons. A very high correlation ( $r$ $=.82$ in female Caucasians, and $r=.90$ in male Caucasians) between the number of nevi on a subject's trunk and the number of nevi on his or her entire body has been shown previously (16). Recognition and classification of nevi and dysplastic nevi from photographs have been shown to be accurate and reproducible $(17,18)$. To be defined as dysplastic, a nevus had to be $5 \mathrm{~mm}$ or larger, had to be predominantly flat, and had to have at least two of the following criteria: variable pigmentation, indistinct borders, and irregular outline (19). Nevi $(4,20,21)$ and dysplastic nevi $(4,22)$ tend to disappear with age, making their diagnosis difficult to assess in older individuals (4). We, thus, excluded subjects (34 case patients and 15 control subjects) older than 60 years from all of the analyses that included dysplastic nevi and nevi.

\section{DNA Repair Assay}

DRC was measured in cryopreserved lymphocytes by the host-cell reactivation assay, as described by Athas et al. (14). Blood samples were stored before analysis for 2-30 months. All of the analyses were performed blinded to the case status. Briefly, plasmid DNA containing a chloramphenicol acetyltransferase (CAT) reporter gene was UV irradiated $(254 \mathrm{~nm}$ at 0,350 , and $700 \mathrm{~J} / \mathrm{m}^{2}$ ) before transfection. Peripheral blood lymphocytes, incubated for 72 hours with phytohemagglutinin, were then transfected with undamaged or UV radiation-damaged plasmid DNA. The amount of plasmid used in the assay was optimized and validated previously (14). Cells were incubated for another 40 hours to allow the repair of damaged genes in the plasmid, including the CAT gene. Gene expression was then measured as CAT activity, expressed as counts per minute (cpm) of $\left[{ }^{3} \mathrm{H}\right]$ acetylchloramphenicol. DRC was calculated as the percentage of residual CAT gene expression after the repair of UV radiation-damaged plasmid DNA divided by that in undamaged plasmid DNA (100\%). The background level of CAT activity was approximately $200 \mathrm{cpm}$. Xeroderma pigmentosum D (XPD) and xeroderma pigmentosum A (XPA) cells were used as positive controls. After 254-nm irradiation at $350 \mathrm{~J} / \mathrm{m}^{2}$, the repair activity was about $2 \%$ in XPD cells and $0.8 \%$ in XPA cells. After irradiation at $700 \mathrm{~J} / \mathrm{m}^{2}$, DRC was about $0.7 \%$ in XPD and $0.3 \%$ in XPA.

Each sample was assayed twice, and a very high correlation was observed between the two repeats $(r=.89$ for CAT activity at baseline level, $r=.91$ after irradiation with $350 \mathrm{~J} / \mathrm{m}^{2}$, and $r$ $=.88$ after irradiation with $700 \mathrm{~J} / \mathrm{m}^{2}$ ). Results reported reflect the average of the two repeats. DRC was measured from nine to 12 times in three control samples (one primary cell sample from a healthy volunteer, one cell line from a healthy subject, and one xeroderma pigmentosum C [XPC] cell line, whose DRC is intermediate between XPD DRC and that of healthy individuals [after irradiation at $350 \mathrm{~J} / \mathrm{m}^{2}$, DRC is about $9.8 \%$, and after irradiation at $700 \mathrm{~J} / \mathrm{m}^{2}$, DRC is about $1 \%$ ]) to assess the assay's reproducibility among different batches. DRC after irradiation with $350 \mathrm{~J} / \mathrm{m}^{2}$ had a lower coefficient of variation than DRC after irradiation with $700 \mathrm{~J} / \mathrm{m}^{2}(27.8 \%$ versus $51.7 \%$, respectively) in these three samples. In all of the analyses, results based on DRC values measured after irradiation with 350 and $700 \mathrm{~J} / \mathrm{m}^{2}$ were very similar. Consequently, we report only results obtained after irradiation with $350 \mathrm{~J} / \mathrm{m}^{2}$. Cell viability, baseline CAT activity, and blastogenic rate were similar in subjects recruited in different seasons. CAT activity of less than $1000 \mathrm{cpm}$ in unirradiated cells is required to accurately measure DRC with a signal-to-noise ratio at least twofold higher than the background level $(200 \mathrm{cpm})$ in cells with irradiated plasmids. Therefore, subjects with baseline CAT activity of less than $1000 \mathrm{cpm}$ (51 [27.9\%] of 183 case patients and 34 [19.0\%] of 179 control subjects) were excluded from the analysis. Thus, we analyzed data from 132 case patients and from 145 age- and sex-matched control subjects. The mean age was slightly higher $(P=.03)$ in the excluded subjects (mean \pm standard deviation $[S D]=50.4$ \pm 14.8 years) than in those included in the study $(46.2 \pm 14.1$ years). No other statistically significant differences were found 
Table 1. Characteristics of study subjects and risk of $\mathrm{CMM}^{*}$

\begin{tabular}{|c|c|c|c|c|c|c|}
\hline & \multirow[b]{2}{*}{$\begin{array}{l}\text { Case patients } \\
(\mathrm{n}=132)\end{array}$} & \multirow[b]{2}{*}{$\begin{array}{l}\text { Control subjects } \\
\quad(\mathrm{n}=145)\end{array}$} & \multicolumn{2}{|c|}{ Adjusted for age and sex } & \multicolumn{2}{|c|}{$\begin{array}{l}\text { Adjusted for age, sex, } \\
\text { and host characteristics } \ddagger\end{array}$} \\
\hline & & & $\begin{array}{l}\text { OR for CMM } \\
\quad(95 \% \mathrm{CI})\end{array}$ & $\begin{array}{l}P \text { for } \\
\text { trend } \dagger\end{array}$ & $\begin{array}{l}\text { OR for CMM } \\
\quad(95 \% \mathrm{CI})\end{array}$ & $\begin{array}{l}P \text { for } \\
\text { trend } \dagger\end{array}$ \\
\hline \multicolumn{7}{|l|}{ Sex, No. $(\%)$} \\
\hline Males & $63(47.7)$ & $75(51.7)$ & & & & \\
\hline Females & $69(52.3)$ & $70(48.3)$ & & & & \\
\hline Mean age, y $( \pm \mathrm{SD})$ & $48.0( \pm 15.0)$ & $44.6( \pm 12.9)$ & & & & \\
\hline \multicolumn{7}{|c|}{ Mean CAT activity, cpm $\times 1000(95 \%$ CI $)$} \\
\hline Baseline & $21.6(17.7$ to 25.5$)$ & $23.2(19.3$ to 27.1$)$ & & & & \\
\hline $350 \mathrm{~J} / \mathrm{m}^{2}$ & $4.5(3.7$ to 5.3$)$ & $4.7(3.8$ to 5.7$)$ & & & & \\
\hline $700 \mathrm{~J} / \mathrm{m}^{2}$ & $1.5(1.2$ to 1.7$)$ & $1.6(1.2$ to 2.0$)$ & & & & \\
\hline \multicolumn{7}{|l|}{ Hair color, No. $(\%) \S$} \\
\hline Black & $8(6.2)$ & $23(16.2)$ & 1.0 (referent) & & 1.0 (referent) & \\
\hline Dark brown & $64(49.2)$ & $79(55.6)$ & $3.0(1.2$ to 7.5$)$ & & $2.2(0.7$ to 6.9$)$ & \\
\hline Light/reddish brown & $38(29.2)$ & $33(23.2)$ & $4.5(1.7$ to 12.3$)$ & & $2.1(0.6$ to 7.1$)$ & \\
\hline Blond & $18(13.9)$ & $7(4.9)$ & $9.9(2.8$ to 34.9$)$ & & $2.6(0.6$ to 12.2$)$ & .270 \\
\hline Red & $2(1.5)$ & $0(0)$ & - & $<.001$ & - & \\
\hline \multicolumn{7}{|l|}{ Eye color, No. (\%)\| } \\
\hline Dark & $32(24.2)$ & $61(42.1)$ & 1.0 (referent) & & 1.0 (referent) & \\
\hline Medium & $72(54.6)$ & $72(49.7)$ & $2.0(1.2$ to 3.6$)$ & & $1.9(1.0$ to 3.5$)$ & \\
\hline Light & $28(21.2)$ & $12(8.3)$ & $4.8(2.1$ to 10.9$)$ & $<.001$ & $4.4(1.7$ to 11.3$)$ & .002 \\
\hline \multicolumn{7}{|l|}{ Skin color, No. $(\%) \S$} \\
\hline Dark/olive & $3(2.3)$ & $22(15.2)$ & 1.0 (referent) & & 1.0 (referent) & \\
\hline Medium & $52(39.7)$ & $74(51.0)$ & $4.3(1.2$ to 15.3$)$ & & $2.7(0.7$ to 11.2$)$ & \\
\hline Light & $76(58.0)$ & $49(33.8)$ & $10.4(2.9$ to 37.1$)$ & $<.001$ & $4.3(1.0$ to 18.8$)$ & .039 \\
\hline \multicolumn{7}{|l|}{ Freckles, No. $(\%) \S$} \\
\hline No & $55(42.0)$ & $74(51.7)$ & 1.0 (referent) & & 1.0 (referent) & \\
\hline Yes & $76(58.0)$ & $69(48.3)$ & $1.5(0.9$ to 2.5$)$ & & $1.0(0.5$ to 1.8$)$ & \\
\hline \multicolumn{7}{|c|}{ Tanning ability after prolonged sun exposure, No. (\%)§ } \\
\hline High & $21(16.4)$ & $52(36.9)$ & 1.0 (referent) & & 1.0 (referent) & \\
\hline Medium & $62(48.4)$ & $71(50.4)$ & $2.0(1.1$ to 3.7$)$ & & $1.1(0.5$ to 2.4$)$ & \\
\hline Low & $45(35.2)$ & $18(12.8)$ & $6.0(2.8$ to 12.9$)$ & $<.001$ & $3.4(1.3$ to 8.7$)$ & .009 \\
\hline \multicolumn{7}{|c|}{ Skin response to $30 \mathrm{~min}$ in the sun, No. $(\%) \S$} \\
\hline Tan without burn & $31(24.2)$ & $53(37.3)$ & 1.0 (referent) & & 1.0 (referent) & \\
\hline Light/medium burn & $63(49.2)$ & $67(47.2)$ & $1.6(0.9$ to 2.8$)$ & & $1.1(0.6$ to 2.2$)$ & \\
\hline Severe burn/blistering & $34(26.6)$ & $22(15.5)$ & $3.0(1.5$ to 6.2$)$ & .003 & $1.1(0.4$ to 2.5$)$ & .868 \\
\hline \multicolumn{7}{|c|}{ Dysplastic nevi, No. (\%)§,đI } \\
\hline No & 44 (48.9) & $96(82.1)$ & 1.0 (referent) & & 1.0 (referent) & \\
\hline Yes & $46(51.1)$ & $21(17.9)$ & $5.0(2.6$ to 9.6$)$ & & $4.3(2.1$ to 8.9$)$ & \\
\hline \multicolumn{7}{|l|}{ Nevi, No. $(\%) \S, \Phi$} \\
\hline $0-20$ & $14(15.7)$ & $44(35.8)$ & 1.0 (referent) & & 1.0 (referent) & \\
\hline $20-40$ & 29 (32.6) & $38(30.9)$ & $2.7(1.2$ to 6.0$)$ & & $2.1(0.8$ to 5.4$)$ & \\
\hline $40-190$ & $46(51.7)$ & $41(33.3)$ & $4.2(2.0$ to 9.1$)$ & $<.001$ & $2.2(0.8$ to 5.9$)$ & .135 \\
\hline \multicolumn{7}{|c|}{ Sunburns with blisters, No. in lifetime (\%) } \\
\hline None & $108(81.8)$ & $121(83.4)$ & 1.0 (referent) & & 1.0 (referent) & \\
\hline $1-5$ & $13(9.9)$ & $20(13.8)$ & $0.8(0.4$ to 1.6$)$ & & $0.7(0.3$ to 1.7$)$ & \\
\hline$>5$ & $11(8.3)$ & $4(2.8)$ & $3.5(1.0$ to 11.5$)$ & .192 & $1.8(0.5$ to 7.1$)$ & .814 \\
\hline
\end{tabular}

${ }^{*} \mathrm{CMM}=$ cutaneous malignant melanoma; $\mathrm{OR}=$ odds ratio; $\mathrm{CI}=$ confidence interval; $\mathrm{SD}=$ standard deviation; $\mathrm{cpm}=\mathrm{counts}$ per minute. $\dagger$ Test for trend across classes.

‡ORs and 95\% CIs adjusted for age, sex, eye color, skin color, tanning ability after prolonged sun exposure, and presence of dysplastic nevi. $\S$ Total number of subjects may vary across variables because of missing values.

$\|$ Low risk = black or dark brown; medium risk = light brown, brown-green, green, or blue-green; high risk = light blue, dark blue, or gray.

ISSubjects older than 60 years of age were excluded from the analysis. All statistical tests are two-sided.

between the two groups. The characteristics of the entire group of 183 case patients and 179 control subjects were reported elsewhere (23). Baseline and induced CAT activities are reported in Table 1 . In subjects $(\mathrm{n}=59)$ with a baseline CAT activity between 1000 and $5000 \mathrm{cpm}$, DRC levels had statistically significantly higher variability $(\mathrm{SD}=17.2 \%)$ than in subjects with a CAT activity of more than $5000 \mathrm{cpm}(\mathrm{SD}=8.8 \%)$ $(P<.001$, test on equality of variances $)$.

\section{Statistical Analysis}

Adjusted odds ratios (ORs), 95\% confidence intervals (CIs), and tests for trend were computed by use of multiple logistic regression models, including matching variables (i.e., age and sex) as independent variables. Cell viability and length of sample storage were slightly associated with case status (median cell viability $=69.9 \%$ in case patients and $73.7 \%$ in control 
subjects, $P=.05$; median storage length $=8.5$ months in case patients and 6.0 months in control subjects, $P=.09$ ) and with DRC (correlation between DRC and viability, $r_{s}=-.26$ $[P<.001]$; correlation between DRC and sample storage length, $\left.r_{s}=.11[P=.07]\right)$. Thus, all of the analyses that included DRC were adjusted for both cell viability and length of sample storage. Results shown throughout this article were not adjusted by baseline CAT activity and blastogenic rate because these variables were associated with neither DRC nor case status, and their inclusion in the analyses did not change the results. The presence of statistically significant interactions among variables in the models was tested by use of a likelihood-ratio test. Forward stepwise regression analysis was used to identify the strongest risk factors for CMM risk. Likelihood-ratio $\chi^{2}$ (LRX) was used to select the most statistically significant factors to be added to the initial logistic model. Variables with a $P$ value of less than .05 entered the model; those with a $P$ value of .10 or more were removed from the model. Wilcoxon (Mann-Whitney) rank-sum and Kruskal-Wallis tests were used for single-group and multiple-group comparisons, respectively. Proportions were compared by use of Fisher's exact test. Spearman rank correlation statistics was used to test for linear correlation between variables. All statistical tests were two-sided. Results are not stratified by sex because they were similar in the two sexes. All of the analyses were performed by use of the Stata statistical package (release 6.0; Stata Corporation, College Station, TX).

\section{RESUltS}

\section{Subject Characteristics}

The personal characteristics of the 132 case patients with CMM and of the 145 control subjects for whom DRC could be determined are shown in Table 1 . In order of relative statistical significance, the strongest risk factors for CMM identified by stepwise regression analyses were the presence of dysplastic nevi $(\mathrm{LRX}=26.5 ; P<.001)$ and a tanning response after prolonged sun exposure $(\mathrm{LRX}=18.2 ; P<.001)$. Eye color and skin color were lower predictors of $\mathrm{CMM}$ risk $(\mathrm{LRX}=11.5$ $[P=.003]$ and LRX $=7.7[P=.022]$, respectively) .

\section{DRC by Subject Characteristics}

The median DRC values by sex, age, tanning ability, and sun exposure are shown in Table 2, stratified by case status, the presence of dysplastic nevi, and the number of nevi $(<35$ nevi versus $\geqslant 35$ nevi). DRC decreased with age in control subjects lacking dysplastic nevi $(P=.05)$ or with few nevi $(P=.05)$ but increased with age in control subjects with dysplastic nevi $(P=.02)$ or with many nevi $(P=.24)$. There was no association

Table 2. Median DNA repair capacity (DRC)* after 254-nm UV irradiation $\left(350 \mathrm{~J} / \mathrm{m}^{2}\right)$ by subjects' characteristics

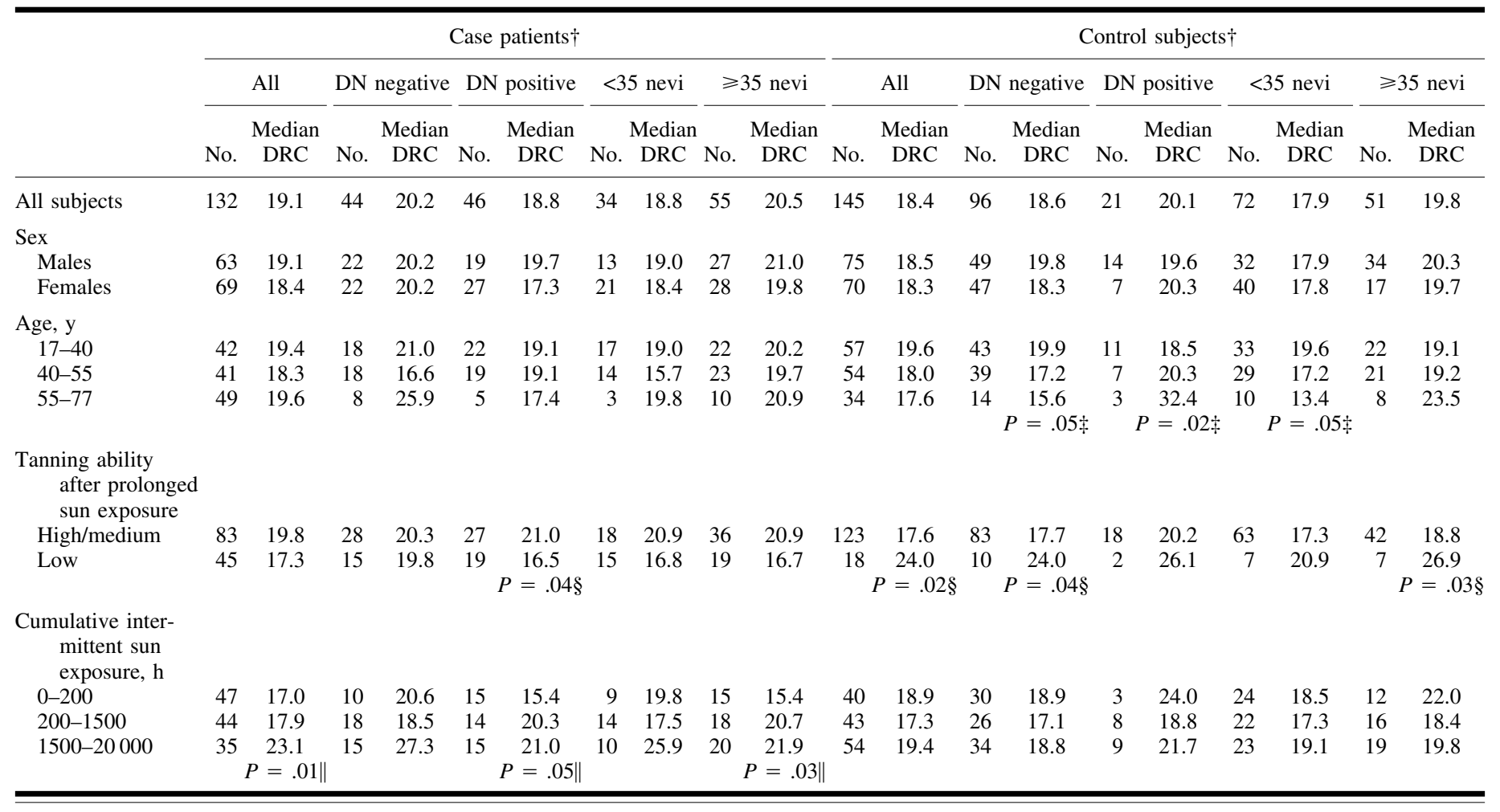

*DRC was calculated as the percentage of residual chloramphenicol acetyltransferase gene expression after the repair of UV radiation-damaged plasmid DNA divided by that in undamaged plasmid DNA $(100 \%)$.

$\dagger$ Total number of subjects may vary because of missing values. Nevus count is missing in two subjects because pictures did not include the entire back. Dysplastic nevus (DN) diagnosis was uncertain in seven subjects; thus, DN was recorded as missing. Fourteen subjects who lacked photographs and 49 subjects older than 60 years were excluded from the analyses with DN and number of nevi; thus, the total number of subjects in these categories is lower than the total number of case patients and control subjects. Approximately 83\% of subjects with DN also had 35 or more nevi, and 66\% of subjects without DN had fewer than 35 nevi. Age and sun exposure categories were approximately based on tertiles. All statistical tests are two-sided.

$¥$ Spearman rank correlation test for the association between DRC and age.

$\S$ Wilcoxon (Mann-Whitney) rank-sum test for differences between high/medium versus low tanning ability.

||Spearman rank correlation test for the association between DRC and recreational sun exposure. 
Table 3. Risk of cutaneous malignant melanoma (CMM) by DNA repair capacity (DRC)*

\begin{tabular}{|c|c|c|c|c|c|c|c|c|}
\hline \multirow[b]{3}{*}{ DRC, $\%$} & \multirow{3}{*}{$\begin{array}{c}\text { No. of } \\
\text { case patients }\end{array}$} & \multirow{3}{*}{$\begin{array}{c}\text { No. of } \\
\text { control subjects }\end{array}$} & \multicolumn{6}{|c|}{ CMM relative risk } \\
\hline & & & \multicolumn{2}{|c|}{$\begin{array}{l}\text { Adjusted for age and sex } \\
\qquad(\mathrm{n}=277)\end{array}$} & \multicolumn{2}{|c|}{$\begin{array}{c}\text { Adjusted for } \\
\text { laboratory varaiables } \uparrow \\
(\mathrm{n}=277)\end{array}$} & \multicolumn{2}{|c|}{$\begin{array}{l}\text { Adjusted for laboratory variables } \\
\text { and host characteristics } \neq \\
\qquad(\mathrm{n}=201) \S\end{array}$} \\
\hline & & & OR & $95 \% \mathrm{CI}$ & OR & $95 \% \mathrm{CI}$ & OR & $95 \% \mathrm{CI}$ \\
\hline$\leqslant 18.4$ & 64 & 73 & 0.9 & 0.5 to 1.4 & 1.0 & 0.6 to 1.7 & 1.0 & 0.5 to 2.0 \\
\hline$>18.4$ & 68 & 72 & 1.0 & Referent & 1.0 & Referent & 1.0 & Referent \\
\hline
\end{tabular}

*DRC above or below the median value $(18.4 \%)$ in control subjects, after 254 -nm UV irradiation at $350 \mathrm{~J} / \mathrm{m}^{2}$. OR $=$ odds ratio; CI $=$ confidence interval. $\dagger \mathrm{OR}$ and $95 \% \mathrm{CI}$ adjusted for age, sex, cell viability, and storage length.

$\ddagger \mathrm{OR}$ and $95 \% \mathrm{CI}$ adjusted for age, sex, cell viability, storage length, skin color, eye color, propensity to tan after prolonged sun exposure, and presence of dysplastic nevi.

$\S$ Subjects older than 60 years and/or missing values were excluded from the analysis.

between DRC and age in the case group. When subjects were stratified by tanning ability (medium/high versus low), no association between DRC and age was observed (data not shown). Among control subjects, those with a lower tanning ability had a higher DRC. Among case patients, there was no substantive difference in DRC by tanning ability, except an inverse statistically significant association in those with dysplastic nevi.

Among case patients, DRC was positively associated with recreational lifetime sun exposure (between $11 \mathrm{AM}$ and $3 \mathrm{PM}$ ) $(P=.01)$, particularly in those with dysplastic nevi $(P=.05$ for case patients with dysplastic nevi, and $P=.09$ for case patients without dysplastic nevi). No association was found between DRC and melanoma characteristics, including histologic subtypes $(P=.39)$, thickness $(P=.70)$, or Clark's level $(P=.71)$.

No statistically significant association was observed in all study subjects between DRC and hair color $(P=.49)$, eye color $(P=.72)$, skin color $(P=.20)$, freckles $(P=.39)$, propensity to tan after prolonged sun exposure $(P=.29)$, skin response after the first 30 minutes in the sun $(P=.98)$, use of photosensitizing drugs $(P=.72)$, vitamin intake $(P=.96)$, or smoking exposure $(P=.28)$.

\section{Sun Exposure and CMM Risk}

The majority of subjects (57\% of case patients and 59\% of control subjects) did not work outside, and occupational sun exposure was not associated with CMM risk. Many subjects reported prolonged recreational (intermittent) sun exposure, which differed slightly between case patients and control subjects $(P=.15$, test for trend for exposure categories, after adjusting for age, sex, and pigmentation characteristics). Among control subjects, cumulative intermittent sun exposure did not differ by dysplastic nevus status $(P=.37)$.

\section{CMM Risk by DRC}

Overall, we found no statistically significant association between CMM risk and DRC ( $\mathrm{OR}=1.0$ [95\% $\mathrm{CI}=0.6$ to 1.7], adjusted for age, sex, cell viability, and storage length) (Table 3). We then evaluated the two strongest melanoma risk factors, tanning ability and dysplastic nevi (Table 4), and found that DRC strongly influenced CMM risk in individuals with a low tanning ability or dysplastic nevi. Subjects with both a low DRC and a low tanning ability had an OR for CMM of 8.6 (95\% CI $=2.7$ to 27.5) compared with subjects with a high DRC and a high/medium tanning ability. The joint effect of DRC and tanning ability was much larger than the sum of the individual effects (i.e., there was an interaction) in the logistic regression equation $(P=.001)$. Among subjects with a low tanning ability, those with a low DRC had a fivefold higher relative risk of melanoma $(\mathrm{OR}=4.9$ [95\% CI $=1.4$ to 17.3$]$, adjusted for age and sex) than those with a high DRC.

Subjects with both a low DRC and dysplastic nevi had a higher relative risk for $\mathrm{CMM}(\mathrm{OR}=6.7 ; 95 \% \mathrm{CI}=2.4$ to 18.6) than subjects without dysplastic nevi and with a high DRC. Subjects with dysplastic nevi and a high DRC had an intermediate relative risk $(\mathrm{OR}=2.9 ; 95 \% \mathrm{CI}=1.2$ to 6.7$)$. Among subjects with dysplastic nevi, those with a low DRC had an OR for CMM of 1.9 (95\% CI $=0.6$ to 5.8, adjusted for age and sex) compared with subjects with a high DRC. Results were similar in subjects with a high number of nevi (data not shown). The test for interaction between DRC and dysplastic nevus status was marginally statistically significant $(P=.04)$.

Only two control subjects had both dysplastic nevi and a low tanning ability. When the model for CMM relative risk associated with tanning ability and DRC was adjusted for the presence

Table 4. Risk of cutaneous malignant melanoma (CMM) and DNA repair capacity (DRC), by tanning ability after prolonged sun exposure and presence of dysplastic nevi (DN)

\begin{tabular}{|c|c|c|c|c|}
\hline & & $\begin{array}{c}\text { No. of } \\
\text { case patients }\end{array}$ & $\begin{array}{c}\text { No. of } \\
\text { control subjects }\end{array}$ & OR $(95 \% \mathrm{CI})^{*}$ \\
\hline $\mathrm{DRC} \dagger$ & Tanning ability & & & \\
\hline Low & Low & 26 & 4 & $8.6 \ddagger(2.7$ to 27.5$)$ \\
\hline High & Low & 19 & 14 & $1.5 \ddagger(0.6$ to 3.5$)$ \\
\hline Low & High/medium & 35 & 68 & $0.6 \ddagger(0.3$ to 1.1$)$ \\
\hline High & High/medium & 48 & 55 & $1.0 \ddagger$ (referent) \\
\hline $\mathrm{DRC}^{\dagger}$ & DN§ & & & \\
\hline Low & Positive & 23 & 7 & $6.7 \|(2.4$ to 18.6$)$ \\
\hline High & Positive & 23 & 14 & $2.9 \|(1.2$ to 6.7$)$ \\
\hline Low & Negative & 17 & 47 & $0.6 \|(0.2$ to 1.3$)$ \\
\hline High & Negative & 27 & 49 & $1.0 \|($ referent $)$ \\
\hline
\end{tabular}

*Odds ratios (ORs) and 95\% confidence intervals (CIs) adjusted for age, sex, cell viability, and storage length.

$\lceil$ DRC above or below the median value (18.4\%) in control subjects, after 254-nm UV irradiation at $350 \mathrm{~J} / \mathrm{m}^{2}$.

$\ddagger$ Likelihood-ratio test for the interaction between DRC and tanning ability: $P=.001$.

$\S$ Subjects older than 60 years were excluded from the analysis.

|Likelihood-ratio test for the interaction between DRC and presence of DN: $P=.04$. All statistical tests are two-sided. 
of dysplastic nevi, the ORs did not substantially change (OR = $14.5[95 \% \mathrm{CI}=2.9$ to 73.6$]$ for subjects with a low DRC and a low tanning ability; $\mathrm{OR}=2.3[95 \% \mathrm{CI}=0.8$ to 6.6] for subjects with a high DRC and a low tanning ability; OR $=0.6$ [95\% CI $=0.3$ to 1.3] for subjects with a low DRC and a high/medium tanning ability). Similarly, when the model for CMM risk associated with the presence of dysplastic nevi and DRC was adjusted for tanning ability, the ORs did not change substantially $(\mathrm{OR}=6.7[95 \% \mathrm{CI}=2.2$ to 20.6] for subjects with a low DRC and dysplastic nevi; OR $=3.3[95 \% \mathrm{CI}=1.3$ to 8.1] for subjects with a high DRC and dysplastic nevi; OR = $0.6[95 \% \mathrm{CI}=0.3$ to 1.5$]$ for subjects with a low DRC but without dysplastic nevi). Thus, interactions between DRC and the tanning response and between DRC and the dysplastic nevus status were independently associated with CMM risk.

No association between sun exposure (above or below 700 cumulative peak hours of intermittent exposure during lifetime) and CMM risk by DRC levels was observed (data not shown).

\section{CMM Risk in Subgroups}

In the subset of 218 individuals with a CAT activity of greater than $5000 \mathrm{cpm}$, the findings were comparable to those obtained in the larger study group. When the hospital volunteers and subjects with minor trauma from the control group were excluded and then all of the analyses were repeated, the results were not substantially different from those reported throughout this article. Of note, in the subset of subjects with a basal CAT activity of more than $5000 \mathrm{cpm}$ and with only case spouses or friends as control subjects, the relative risk for CMM in people with a low DRC and a low tanning ability was even stronger than that in the entire dataset after adjustment for age, sex, length of sample storage, and cell viability $(\mathrm{OR}=20.1[95 \% \mathrm{CI}=2.5$ to 162.8]; $P=.002$, test for interaction between DRC and tanning ability). In the same subset (but with individuals $<60$ years old), subjects with a low DRC and dysplastic nevi had an OR for CMM of $8.3(95 \% \mathrm{CI}=2.0$ to 35.0$)$, and the interaction between dysplastic nevi and DRC was statistically significant $(P=.006)$.

\section{Discussion}

Human subjects typically display a range of inherent sensitivities to sunlight exposure, possibly because of differences in skin pigmentation and in the ability to repair DNA damage. The highest world's rates of CMM are in Australia, where a largely Celtic population inhabits a subtropical zone (24). In Europe, CMM rates tend to be lower in southern countries (25), where high levels of UV radiation are present and relatively dark skin predominates. CMM may be caused by intermittent exposure of nonacclimatized Caucasian skin to sunlight, which may result in repeated burning $(6,26,27)$. In contrast, continuous sun exposure able to induce persistent tanning in those who tan well may be somewhat protective against melanoma (28). CMM relative risk may increase proportionally to the dose received by nontanned skin (27) and to the capacity of that skin to repair sunlightinduced DNA damage. We found similar DNA repair proficiency in subjects with and without melanoma; thus, the inherent capacity to repair DNA damage did not affect overall CMM risk (Table 3). However, among subjects with a low tanning ability or with dysplastic nevi, the relative risk of melanoma was statistically significantly modified by DRC (Table 4).
The finding that tanning ability statistically interacts with DRC in its association with the relative risk of melanoma is supported by data on melanin and its association with DNA damage (29-31). Two distinct types of melanin are present in human skin: the red-yellow pheomelanin and the brown-black eumelanin. The presence of eumelanin corresponds to the sun sensitivity of skin: the higher the concentration of eumelanin, the lower the sun sensitivity (29). Pheomelanin protects skin less well against UV radiation-induced damage (30) and may generate free radicals on exposure to UV radiation (31). Although the association among pigmentation characteristics, such as hair color, and the density and type of melanin is still under study (32), DNA repair proficiency may be of great importance in subjects with a poor tanning response, who have an increased propensity to DNA damage and an increased relative risk of CMM (Table 1). Indeed, in our study, the relative risk of CMM was nine times higher in subjects with both a low tanning ability and a low DRC than in subjects with a high/medium tanning ability and a high DRC (Table 4). We did not find a similar interaction with other pigmented characteristics, such as the color of skin, eyes, or hair, perhaps because these variables were less strongly associated with melanoma than the presence of dysplastic nevi and tanning ability, as shown by the forward stepwise regression analysis.

The risk of melanoma associated with dysplastic nevi appears to be modified by DRC. Subjects at an increased risk of melanoma because of dysplastic nevi had an even higher risk when poor DRC was present. The incremental risk associated with a low DRC appears somewhat lower among individuals with dysplastic nevi than among those with a low tanning ability. The effects of dysplastic nevi and tanning ability on CMM risk seemed to be independent.

Dysplastic nevi are recognized risk factors for and precursor lesions of melanoma. In individuals with dysplastic nevi, a low DRC may result in higher mutation rates and, consequently, in increased rates of melanoma (Table 4). Indeed, studies $(33,34)$ on bleomycin- and x-ray-induced DNA damage in subjects with CMM and dysplastic nevi found that patients with both CMM and dysplastic nevi had a statistically significantly higher sensitivity to mutagens than patients with only dysplastic nevi. In contrast, no statistically significant difference in DRC was observed between individuals with dysplastic nevi from melanoma-prone families and healthy control subjects (35).

As shown in Table 4, individuals with a low DRC and either a high/medium tanning ability or no dysplastic nevi appeared at somewhat lower risk than the reference groups. We, therefore, evaluated the distribution of other risk factors. Among subjects with a high/medium tanning ability, those with a low DRC were less likely to have dysplastic nevi and had slightly lower sun exposure and fewer nevi than those with a high DRC. Similarly, among subjects without dysplastic nevi, those with a low DRC had slightly lower sun exposure and a higher tanning ability than those with a high DRC.

In control subjects with dysplastic nevi, DRC increased with age. Early studies (36-38) suggested that individuals with dysplastic nevi may have a high genomic instability. Mammalian cells with accumulating sublethal mutations appear to have enhanced DRC $(39,40)$, and in vitro UV radiation appears to stimulate DNA repair activity (39). Thus, the accumulating mutations in subjects with a high genomic instability may continuously induce DNA repair activity, which would explain the age- 
associated elevation in DRC observed in control subjects with dysplastic nevi. In control subjects without dysplastic nevi, DRC decreases with age, as shown previously (41). Subjects with dysplastic nevi and a low inducible DNA repair activity may accumulate mutations, which, consequently, can increase their risk of melanoma. In fact, in our study, DRC was not associated with age in case patients, even in those with dysplastic nevi.

Sun exposure is considered to be the major environmental risk factor for melanoma, based largely on retrospective studies of fair-skinned populations (27). In Italy, the association between sun exposure and melanoma risk has been less consistent (42-46). In our study, all of the subjects lived in the same geographic area, most for their entire lifetime. In addition, because most control subjects were spouses or partners of the case patients, these groups had a similar adult sun exposure. This similarity with regard to sun exposure was appropriate for our investigation. Our goal was to identify subjects at high risk for melanoma because of their inherited characteristics, independent of sun exposure.

We also considered potential sources of bias or confounding. Selection bias is unlikely because we ascertained virtually all of the case patients in the study area, we obtained a high response rate from case patients and control subjects, and we observed essentially no difference after exclusion of the two smaller groups of control subjects. One dermatologist assessed the subjects' pigmentation characteristics and skin lesions. After exclusion of subjects older than 60 years, one oncologist, blinded to case status, assessed dysplastic nevus diagnoses and nevus counts from photographs of the back of each subject. Because dysplastic nevi tend to disappear with age, misclassification of dysplastic nevus status in older subjects is a concern. To be consistent and more conservative, we excluded subjects older than 60 years, even though this exclusion reduced the sample size. Including the entire group of subjects in the analyses, however, did not substantially change the results from those obtained including only subjects 60 years old or younger (data not shown).

Our investigation measured the DRC in lymphocytes with the host-cell reactivation assay, which measures the global level of DNA repair rather than a specific enzymatic step in the repair process. We did not measure DRC in melanocytes because they constitute only $5 \%-10 \%$ of skin cells. In a small study conducted on epidermal cells after UV irradiation, Xu et al. (47) showed no association between DRC and CMM risk, in agreement with this study (Table 3). Previous studies using the same assay on lymphocytes showed positive associations between a low DRC and the risk of basal cell carcinoma (41), lung cancer (48), and head and neck cancer (49). In our study, we found a high coefficient of variation in the three samples that were assessed multiple times. Two of these samples were cell lines, which have higher variability than primary cells. In addition, variability could reflect the fact that assays were performed in different batches and by two different laboratory investigators on different days. Variability was greater after a higher dose of irradiation, as expected (50). The intrabatch correlation between duplicate analyses, however, was very high.

The host-cell reactivation assay requires considerable technical skill and is sensitive to cell conditions. Because of their low CAT activity, we had to exclude samples from 51 case patients and 34 control subjects, but we observed no major differences by subject characteristics between the excluded and included sub- jects. Thus, a bias caused by this exclusion is unlikely. We attempted to verify assay validity and to reduce random error of measurement, as in a carefully conducted study (50), which found no association between DRC and risk of basal cell carcinoma. Two highly experienced laboratory scientists (M. Hedayati and L. Grossman) performed the assay. These scientists, who were blinded to the case status of the samples, assessed samples from case patients and control subjects simultaneously in the same batches. They performed every assay in duplicate. Every statistical analysis that included DRC was controlled for cell viability and length of sample storage, which were slightly associated with case status and DRC. The results based on the UV dose with the lowest coefficient of variation were presented. We also found that the season during which specimens were collected or smoking history did not affect DRC. In addition, we analyzed a subset of individuals with optimum cell conditions (high viability and high baseline CAT activity) to verify the study findings. No statistically significant differences between this subset and the entire study group were observed. If anything, the association between DRC and CMM risk in subjects with dysplastic nevi or with a low tanning ability was even stronger in this subgroup.

In conclusion, our study suggests that DRC is an important modifier of melanoma risk in the presence of other strong risk factors, such as a low propensity to tan and the presence of dysplastic nevi. As with all statistical interactions that are identified for the first time, replication in an independent study is necessary. The occurrence of melanoma in subjects without dysplastic nevi or with a low sun sensitivity appeared to be independent of DRC.

\section{REFERENCES}

(1) Jemal A, Devesa SS, Fears TR, Hartge P. Cancer surveillance series: changing patterns of cutaneous malignant melanoma mortality rates among whites in the United States. J Natl Cancer Inst 2000;92:811-8.

(2) Dennis LK. Analysis of the melanoma epidemic, both apparent and real: data from the 1973 through 1994 Surveillance, Epidemiology, and End Results Program registry. Arch Dermatol 1999;135:275-80.

(3) Serraino D, Fratino L, Gianni W, Campisi C, Pietropaolo M, Trimarco G, et al. Epidemiological aspects of cutaneous malignant melanoma (review). Oncol Rep 1998;5:905-9.

(4) Tucker MA, Halpern A, Holly EA, Hartge P, Elder DE, Sagebiel RW, et al. Clinically recognized dysplastic nevi. A central risk factor for cutaneous melanoma. JAMA 1997;277:1439-44.

(5) Setlow RB. Spectral regions contributing to melanoma: a personal view. J Investig Dermatol Symp Proc 1999;4:46-9.

(6) Elwood JM, Jopson J. Melanoma and sun exposure: an overview of published studies. Int J Cancer 1997;73:198-203.

(7) IARC Working Group on the Evaluation of Carcinogenic Risk to Humans. Studies of cancer in humans. In: Solar and ultraviolet radiation. Lyon (France): International Agency for Research on Cancer; 1992. p. 73-138.

(8) Black HS, deGruijl FR, Forbes PD, Cleaver JE, Ananthaswamy HN, deFabo EC, et al. Photocarcinogenesis: an overview. J Photochem Photobiol B 1997;40:29-47.

(9) Langley RG, Sober AJ. A clinical review of the evidence for the role of ultraviolet radiation in the etiology of cutaneous melanoma. Cancer Invest 1997;15:561-7.

(10) Bohr VA. DNA repair fine structure and its relations to genomic instability. Carcinogenesis 1995;16:2885-92.

(11) Lehmann AR. Nucleotide excision repair and the link with transcription. Trends Biochem Sci 1995;20:402-5.

(12) Kraemer KH, Lee MM, Andrews AD, Lambert WC. The role of sunlight and DNA repair in melanoma and nonmelanoma skin cancer. The xeroderma pigmentosum paradigm. Arch Dermatol 1994;130:1018-21.

(13) Kraemer KH. Sunlight and skin cancer: another link revealed. Proc Natl Acad Sci U S A 1997;94:11-4. 
(14) Athas WF, Hedayati MA, Matanoski GM, Farmer ER, Grossman L. Development and field-test validation of an assay for DNA repair in circulating human lymphocytes. Cancer Res 1991;51:5786-93.

(15) Parkin DM, Whelan SL, Ferlay J, Raymond L, Young J, editors. Cancer incidence in five continents. Vol VII. Lyon (France): International Agency for Research on Cancer; 1997.

(16) English JS, Swerdlow AJ, MacKie RM, O’Doherty CJ, Hunter JA, Clark J, et al. Site-specific melanocytic naevus counts as predictors of whole body naevi. Br J Dermatol 1988;118:641-4.

(17) Hartge P, Holly EA, Halpern A, Sagebiel R, Guerry D, Elder D, et al. Recognition and classification of clinically dysplastic nevi from photographs: a study of interobserver variation. Cancer Epidemiol Biomarkers Prev 1995;4:37-40.

(18) Cooke KR, Spears GF, Elder DE, Greene MH. Dysplastic naevi in a population-based survey. Cancer 1989;63:1240-4.

(19) Landi MT, Calista D, Landi G, Bernucci I, Bertazzi PA, Clark WH Jr, et al. Clinical characteristics of 20 Italian melanoma-prone families [letter]. Arch Dermatol 1999;135:1554-5.

(20) Green A, Swerdlow AJ. Epidemiology of melanocytic nevi. Epidemiol Rev 1989;11:204-21.

(21) Nicholls EM. Development and elimination of pigmented moles, and the anatomical distribution of primary malignant melanoma. Cancer 1973;32: 191-5.

(22) Halpern AC, Guerry D $4^{\text {th }}$, Elder DE, Trock B, Synnestvedt M, Humphreys T. Natural history of dysplastic nevi. J Am Acad Dermatol 1993;29:51-7.

(23) Landi MT, Baccarelli A, Calista D, Pesatori A, Fears TR, Tucker MA, et al. Combined risk factors for melanoma in a Mediterranean population. Br J Cancer 2001;85:1304-10.

(24) Marrett LD, Nguyen HL, Armstrong BK. Trends in the incidence of cutaneous malignant melanoma in New South Wales, 1983-1996. Int J Cancer 2001;92:457-62.

(25) Ferlay J, Bray F, Sankila R, Parkin DM. EUCAN: cancer incidence, mortality and prevalence in the European Union 1996, version 3.1. IARC CancerBase No. 4. Lyon (France): IARC Press; 1999 (limited version available from: URL: http://www-dep.iarc.fr/eucan/eucan.htm).

(26) MacKie RM. Incidence, risk factors and prevention of melanoma. Eur J Cancer 1998;34 Suppl 3:S3-6.

(27) Armstrong BK, English DR. Cutaneous malignant melanoma. In: Schottenfeld D, Fraumeni JF Jr, editors. Cancer epidemiology and prevention. $2^{\text {nd }}$ ed. New York (NY): Oxford University Press; 1996. p. 1282-312.

(28) Weinstock MA, Colditz GA, Willett WC, Stampfer MJ, Bronstein BR, Mihm MC Jr, et al. Melanoma and the sun: the effect of swimsuits and a "healthy" tan on the risk of nonfamilial malignant melanoma in women. Am J Epidemiol 1991;134:462-70.

(29) Thody AJ, Higgins EM, Wakamatsu K, Ito S, Burchill SA, Marks JM Pheomelanin as well as eumelanin is present in human epidermis. J Invest Dermatol 1991;97:340-4.

(30) Menon IA, Persad S, Ranadive NS, Haberman HF. Effects of ultravioletvisible irradiation in the presence of melanin isolated from human black or red hair upon Ehrlich ascites carcinoma cells. Cancer Res 1983;43:3165-9.

(31) Hill HZ, Li W, Xin P, Mitchell DL. Melanin: a two edged sword? Pigment Cell Res 1997;10:158-61.

(32) Prota G. Melanins, melanogenesis and melanocytes: looking at their functional significance from the chemist's viewpoint. Pigment Cell Res 2000; 13:283-93.

(33) Cloos J, Willems EM, van Warmerdam JM, Braakhuis BJ, Snow GB, Meijer S. Mutagen sensitivity in common cutaneous malignant melanoma and dysplastic naevus syndrome. Melanoma Res 1999;9:292-6.

(34) Sanford KK, Parshad R, Price FM, Tarone RE, Thompson J, Guerry D. Radiation-induced chromatid breaks and DNA repair in blood lymphocytes of patients with dysplastic nevi and/or cutaneous melanoma. J Invest Dermatol 1997;109:546-9.

(35) Hansson J, Loow H. Normal reactivation of plasmid DNA inactivated by
UV irradiation by lymphocytes from individuals with hereditary dysplastic naevus syndrome. Melanoma Res 1994;4:163-7.

(36) Howell JN, Greene MH, Corner RC, Maher VM, McCormick JJ. Fibroblasts from patients with hereditary cutaneous malignant melanoma are abnormally sensitive to the mutagenic effect of simulated sunlight and 4-nitroquinoline 1-oxide. Proc Natl Acad Sci U S A 1984;81:1179-83.

(37) Perera MI, Um KI, Greene MH, Waters HL, Bredberg A, Kraemer KH. Hereditary dysplastic nevus syndrome: lymphoid cell ultraviolet hypermutability in association with increased melanoma susceptibility. Cancer Res 1986;46:1005-9.

(38) Seetharam S, Waters HL, Seidman MM, Kraemer KH. Ultraviolet mutagenesis in a plasmid vector replicated in lymphoid cells from patient with the melanoma-prone disorder dysplastic nevus syndrome. Cancer Res 1989;49:5918-21.

(39) Eller MS, Maeda T, Magnoni C, Atwal D, Gilchrest BA. Enhancement of DNA repair in human skin cells by thymidine dinucleotides: evidence for a p53-mediated mammalian SOS response. Proc Natl Acad Sci U S A 1997;94:12627-32.

(40) Le XC, Xing JZ, Lee J, Leadon SA, Weinfeld M. Inducible repair of thymine glycol detected by an ultrasensitive assay for DNA damage. Science 1998;280:1066-9.

(41) Wei Q, Matanoski GM, Farmer ER, Hedayati MA, Grossman L. DNA repair and aging in basal cell carcinoma: a molecular epidemiology study. Proc Natl Acad Sci U S A 1993;90:1614-8.

(42) Rosso S, Zanetti R, Pippione M, Sancho-Garnier H. Parallel risk assessment of melanoma and basal cell carcinoma: skin characteristics and sun exposure. Melanoma Res 1998;8:573-83.

(43) Zanetti R, Gafa L, Franceschi S, Pippione M, Rosso S. Estimate of the proportion of skin tumors attributable to sun exposure in 3 Italian populations. Epidemiol Prev 1999;23:416-22.

(44) Carli P, Biggeri A, Giannotti B. Malignant melanoma in Italy: risks associated with common and clinically atypical melanocytic nevi. J Am Acad Dermatol 1995;32:734-9.

(45) Cristofolini M, Franceschi S, Tasin L, Zumiani G, Piscioli F, Talamini R, et al. Risk factors for cutaneous malignant melanoma in a northern Italian population. Int J Cancer 1987;39:150-4.

(46) Naldi L, Gallus S, Imberti GL, Cainelli T, Negri E, La Vecchia C. Sunscreens and cutaneous malignant melanoma: an Italian case-control study. Int J Cancer 2000;86:879-82.

(47) Xu G, Snellman E, Bykov VJ, Jansen CT, Hemminki K. Cutaneous melanoma patients have normal repair kinetics of ultraviolet-induced DNA repair in skin in situ. J Invest Dermatol 2000;114:628-31.

(48) Wei Q, Cheng L, Hong WK, Spitz MR. Reduced DNA repair capacity in lung cancer patients. Cancer Res 1996;56:4103-7.

(49) Cheng L, Eicher SA, Guo Z, Hong WK, Spitz MR, Wei Q. Reduced DNA repair capacity in head and neck cancer patients. Cancer Epidemiol Biomarkers Prev 1998;7:465-8.

(50) Hall J, English DR, Artuso M, Armstrong BK, Winter M. DNA repair capacity as a risk factor for non-melanocytic skin cancer-a molecular epidemiological study. Int J Cancer 1994;58:179-84.

\section{NoTES}

Supported by Public Health Service (PHS) grant CA65558-02 (to M. T. Landi) from the National Cancer Institute, National Institutes of Health (NIH), Department of Health and Human Services (DHHS); and by PHS merit award GM22846 (to L. Grossman) from the National Institute of General Medical Sciences, NIH, DHHS.

We are indebted to the study subjects for their participation, to Dr. G. Landi for overseeing the study procedures, and to Dr. D. Calista for the clinical examination and recruitment of study participants. In addition, we thank Drs. G. Ambrosio, N. Caporaso, O. Salvucci, and K. Kraemer for their invaluable inspiration and support.

Manuscript received May 31, 2001; revised October 25, 2001; accepted November 19, 2001. 